\title{
UV Photodissociation Spectroscopy of Oxidized Undecylenic Acid Films
}

\author{
Anthony L. Gomez, Jiho Park, Maggie L. Walser, Ao Lin, and Sergey A. Nizkorodov* \\ Department of Chemistry, University of California, Irvine, Irvine, California 92697-2025
}

Received: September 25, 2005; In Final Form: November 23, 2005

\begin{abstract}
Oxidation of thin multilayered films of undecylenic (10-undecenoic) acid by gaseous ozone was investigated using a combination of spectroscopic and mass spectrometric techniques. The UV absorption spectrum of the oxidized undecylenic acid film is significantly red-shifted compared to that of the initial film. Photolysis of the oxidized film in the tropospheric actinic region $(\lambda>295 \mathrm{~nm})$ readily produces formaldehyde and formic acid as gas-phase products. Photodissociation action spectra of the oxidized film suggest that organic peroxides are responsible for the observed photochemical activity. The presence of peroxides is confirmed by massspectrometric analysis of the oxidized sample and an iodometric test. Significant polymerization resulting from secondary reactions of Criegee radicals during ozonolysis of the film is observed. The data strongly imply the importance of photochemistry in aging of atmospheric organic aerosol particles.
\end{abstract}

\section{Introduction}

Aerosol particles have a tremendous impact on the chemistry and energy balance of the atmosphere. ${ }^{1,2}$ In recent years, chemical processes occurring at aerosol particle-air interfaces have received strong interest from the atmospheric chemistry community. ${ }^{3-11}$ Indeed, the chemical properties of air-particle interfaces affect the ability of particles to act as efficient cloud condensation nuclei $(\mathrm{CCN}){ }^{12}$ The high surface-to-volume ratio of nonaqueous aerosol particles both increases the adsorptivity of the surface and significantly amplifies interface-specific chemical processes. Even in aqueous particles with highly dynamic air-water interfaces, certain anions (e.g., $\mathrm{Cl}^{-}$and $\mathrm{NO}_{3}{ }^{-}$) have been shown to favor the interfacial layer, potentially enhancing the efficiency of chemical reactions involving such ions. ${ }^{7,13}$

This work focuses on mechanisms of chemical and photochemical processes occurring at the air-particle interface in organic aerosols. Numerous field observations of aerosol composition proved that a substantial fraction of tropospheric aerosols can be classified as organic. ${ }^{14-23}$ Even aerosol particles that have traditionally been regarded as inorganic (sea salt, dust, soot) have been shown to carry an organic overcoat. ${ }^{21,24-29}$

Organic aerosols are continuously modified in the atmosphere by chemical reactions with $\mathrm{O}_{3}, \mathrm{O}_{2}, \mathrm{NO}_{3}$, and $\mathrm{OH}^{30-32}$ resulting in a rather complex organic surface composition. Such oxidation of the organic surface is expected to shift its absorption cross section to the red as the aerosol ages. The key question is whether this red shift is significant enough to measurably accelerate aerosol aging via photolysis processes within the particles or even turn organic aerosol particles into sources of small organic molecules and free radicals. Surface photolysis is already known to play a significant role in atmospheric photochemistry, e.g., photolysis of $\mathrm{HNO}_{3}$ into $\mathrm{HONO}$ on surfaces $^{33,34}$ or photochemical production of aldehydes ${ }^{35-37}$ and $\mathrm{HONO}^{38}$ in snowpack. There are strong reasons to believe that aged organic aerosols should also be highly photochemically active.

\footnotetext{
* To whom correspondence should be addressed. E-mail:
} nizkorod@uci.edu.
Ozone is a key oxidant for atmospheric organic molecules containing unsaturated carbon-carbon bonds. ${ }^{39-46}$ The accepted mechanism of ozonolysis of olefins ${ }^{47,48}$ involves a rate-limiting formation of a primary ozonide (POZ) followed by unimolecular decomposition of the POZ into a stable carbonyl and an unstable carbonyl oxide (Criegee intermediate). In nonparticipating solvents, the carbonyl oxide normally reacts with the geminate carbonyl to form a secondary ozonide (SOZ). In the gas phase, collisional stabilization of carbonyl oxides is less efficient, and their fates are dominated by various decomposition and isomerization processes. ${ }^{49-54} \mathrm{In}$ the presence of liquid or gaseous water, acids, or alcohols, the stabilized carbonyl oxide reacts with them to form hydroxylhydroperoxides and related compounds. ${ }^{55-59}$ From the aerosol particle photochemistry point of view, the reactions involved in ozonolysis of olefins are very interesting because they generate many products (aldehydes, peroxides, etc.) with significant photodissociation cross sections in the tropospheric actinic window $(\lambda>295 \mathrm{~nm})$.

To help better understand the importance of photochemical processes occurring at particle-air interfaces in organic aerosols, we studied the photochemistry of thin multilayered films of pure undecylenic acid (10-undecenoic acid) oxidized by gaseous ozone. Although $\omega$-oxocarboxylic (alkene-terminated) acids, such as undecylenic acid, are rarely found in ambient aerosol particles, ${ }^{60}$ larger unsaturated fatty acids and their oxidation products are quite common in organic particulate matter. ${ }^{21,60-62}$ Oxidation of unsaturated fatty acids by ozone has been studied by many researchers. ${ }^{40,42,44,63-68}$ Related reactions of ozone with ordered Langmuir films of phospholipids on water ${ }^{45,46,69}$ or with unsaturated SAM (self-assembled monolayers) ${ }^{39,41,70-73}$ have also been examined. As a result, both the gas-phase and surface products of ozonolysis of unsaturated fatty acids are relatively well understood. This provides a convenient foundation for interpretation of our new results on the photolysis of the oxidized acids.

\section{Experimental Section}

The approach relies on infrared cavity ring-down spectroscopy (IR CRDS) for real-time, sensitive detection of gas-phase molecules in the immediate vicinity of a sample exposed to gas- 


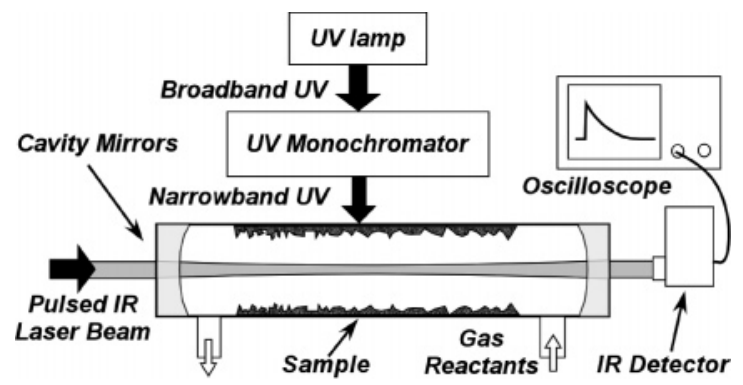

Figure 1. Experimental setup. Quartz flow tube coated with a sample of interest is exposed to gas reactants and/or tunable UV radiation. Gas-phase products are detected using IR CRDS along the flow tube axis.

phase chemicals and/or tunable UV radiation (Figure 1). To prepare the sample, a film of undecylenic acid is spread on the inner walls of a 14-mm inner diameter quartz tube. Undecylenic acid is selected as a model system because of its availability, low vapor pressure, and ease of detection of its ozonolysis products by IR CRDS. The tube is precoated with an organic self-assembled monolayer by treating it with alkylchlorosilanes to improve the uniformity of the undecylenic acid film. ${ }^{71,74-76}$ After application of undecylenic acid, the inside of the tube is thoroughly wiped until it appears fully transparent (the number of molecular layers in the film was not quantified but the film was optically thin in the examined UV spectral range). The loaded tube is placed in a vacuum-tight CRDS cavity. The sample is first oxidized by passing a flow from a commercial ozonizer containing $10^{14-} 10^{15}$ molecule $\mathrm{cm}^{-3}$ of ozone in oxygen through the tube. The ozone density is measured with two homemade absorption cells operating on the $253.65 \mathrm{~nm}$ mercury line (naperian absorption cross section of $\mathrm{O}_{3}$ at 253.65 $\mathrm{nm}$ is $\left.1.136 \times 10^{-17} \mathrm{~cm}^{2}\right) .^{77}$ After the oxidation is complete, the flow of ozone is replaced by a flow of UHP-grade Helium, and the oxidized film is photolyzed. All gas flows into the cavity are measured by calibrated mass-flow controllers. The pressure is measured by a capacitance manometer; most experiments described here are conducted at $1-20$ Torr $(1$ Torr $=133.32$ $\mathrm{Pa})$.

A pair of CRDS cavity mirrors with a stated reflectivity of $99.98 \%$ at $3.3 \mu \mathrm{m}$ is spaced by about $60 \mathrm{~cm}$ and protected by a constant purging flow of dry nitrogen. The cavity is pumped by an IR optical parametric oscillator laser characterized by 0.1 $\mathrm{cm}^{-1}$ spectral resolution, $8 \mathrm{~ns}$ pulse duration, $15 \mathrm{~mJ} /$ pulse energy, and $20 \mathrm{~Hz}$ repetition rate. CRDS experiments described here use a small spectral window around $3.3 \mu \mathrm{m}$ that contains easily distinguishable lines of formic acid and formaldehyde (expected gas-phase products of ozonolysis of undecylenic acid). The CRDS is detected with an InSb detector $(>5 \mathrm{MHz}$ bandwidth), averaged for 20 laser pulses, and digitized with an oscilloscope. A Labview-based program is used to process and store the resulting traces. An optoacoustic spectrum (of $\mathrm{H}_{2} \mathrm{O}$, $\mathrm{CH}_{2} \mathrm{O}$, or $\mathrm{HCOOH}$ ) is recorded in parallel with the CRDS spectrum for wavelength calibration and line identification purposes.

Intrinsic ring-down time is around $\tau_{0}=4-7 \mu \mathrm{s}$, which is close to the theoretical limit of $10 \mu$ s for this cavity configuration. The effective absorption coefficient, $\alpha$, is calculated using a well-known relationship ${ }^{78}$

$$
\alpha\left(\mathrm{cm}^{-1}\right)=\frac{1}{c}\left(\frac{1}{\tau}-\frac{1}{\tau_{0}}\right)
$$

where $c$ is the speed of light, $\tau$ is the ring-down time for a cavity containing an absorber, and $\tau_{0}$ is the intrinsic ring-down time.

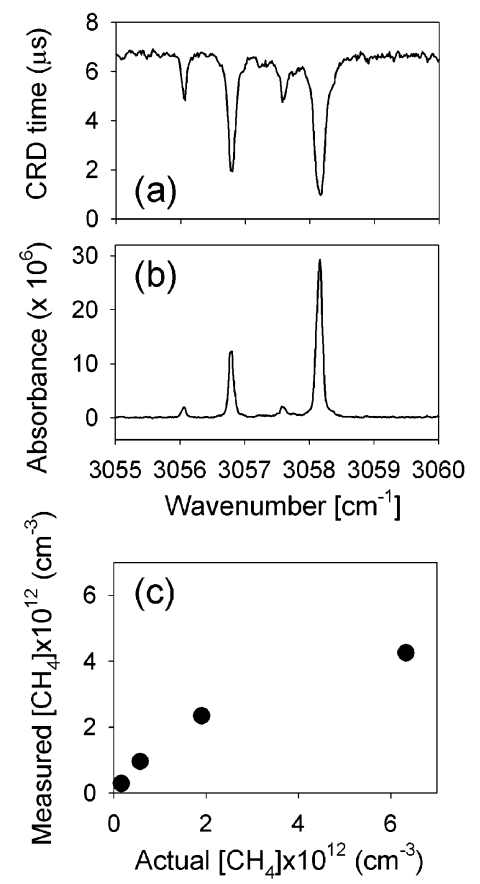

Figure 2. Characterization of the CRDS setup. (a) Cavity ring-down time measured with $1.4 \times 10^{13}$ molecule $/ \mathrm{cm}^{3}$ of $\mathrm{CH}_{4}$ in the cell. (b) Absorbance calculated from the ring-down time. (c) Measured and actual density of $\mathrm{CH}_{4}$. The observed nonlinearity is due to the low spectral resolution of the pump laser.

As the laser line width $\left(0.1 \mathrm{~cm}^{-1}\right)$ is larger than the pressure and Doppler broadened line widths of individual $\mathrm{H}_{2} \mathrm{CO}$ and HCOOH lines $\left(\sim 0.01 \mathrm{~cm}^{-1}\right)$, the method does not actually provide absolute absorbance via $A=\alpha L{ }^{78}$ Furthermore, the cavity ring-down traces are not singly exponential under such conditions, and the presence of mirror-purging flows makes the actual absorption path length $(L)$ somewhat uncertain. Nevertheless, absolute concentrations can still be obtained from the data using an explicit calibration and/or fitting algorithms accounting for the polyexponential decay. Figure 2 shows a representative calibration plot for $\mathrm{CH}_{4}$. The minimal (root-mean-square equivalent) absorption coefficient sensitivity achieved with $1 \mathrm{~s}$ integration time (20 laser shots) is $3 \times 10^{-8} \mathrm{~cm}^{-1}$. This is similar to the detection sensitivity achieved by other pulsed CRDS instruments. ${ }^{78}$ For $\mathrm{CH}_{2} \mathrm{O}$ lines near $3.3 \mu \mathrm{m}$ with integrated line strengths of about $5 \times 10^{-20} \mathrm{~cm}^{2}$ molecule $\mathrm{cm}^{-1}$, this translates into the minimal detectable concentration of $6 \times 10^{10}$ molecule $\mathrm{cm}^{-3}$.

A UV lamp/monochromator illumination system is used for photolysis experiments. The illuminator covers the usual Xe lamp range $(200-800 \mathrm{~nm})$ with a variable $1-20 \mathrm{~nm}$ resolution. The output of the monochromator illuminates a small section $\left(\sim 1 \mathrm{~cm}^{2}\right)$ of the quartz cell. The UV-radiation power is of the order of $10 \mathrm{~mW}$ at $300 \mathrm{~nm}$. The power is considerably lower at lower irradiation wavelengths. Depending on the experiment, photobleaching is accounted for in one of two ways: (i) a different section of the tube is irradiated every two experiments; (ii) photolysis product yields of a specific molecule are monitored throughout the experiment at a reference UV exposure wavelength. In broadband photolysis experiments, the monochromator is replaced by a suitable long-pass or bandpass optical filter. All photolysis experiments are done under UHP He flow conditions.

The experiments are performed in several modes. In the CRDS scanning mode, the UV frequency is fixed while the IR laser is scanned to probe chemical identities of the gas-phase 


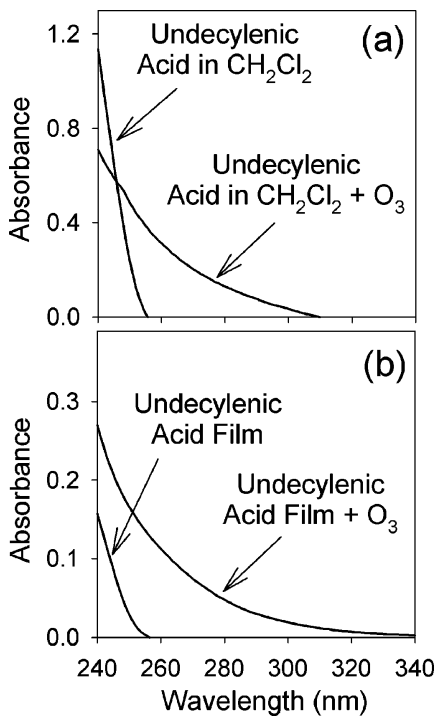

Figure 3. UV absorption spectra of undecylenic acid and its oxidation products. The ozonolysis reaction was carried out: (a) in the liquid phase; (b) on the surface of a thin multilayered film.

photolysis products. In the action spectrum mode, the UV radiation source is tuned while IR frequency is fixed to examine the UV wavelength dependence for a particular photolysis product. The apparatus can also be used in a "reaction mode", wherein the photolysis radiation source is replaced by chemical exposure. In kinetics mode, the CRDS signal is tracked as a function of time with all other conditions fixed.

Because the IR CRDS method does not provide information on the composition of the organic film, it is examined off-line (before and after each experiment) using electrospray ionization mass spectrometry in either positive or negative ion mode. Additionally, the reacted film is characterized by UV/Vis spectroscopy.

\section{Results}

Effect of Ozonolysis on UV/Vis Absorption Spectrum of Undecylenic Acid. The primary goal of this work is to understand the effect of simulated atmospheric oxidation of undecylenic acid on its photochemistry. The initial organic film has no photochemical activity in the tropospheric actinic window $(\lambda>295 \mathrm{~nm})$ because unsaturated fatty acids do not strongly absorb above $250 \mathrm{~nm}$. Figure 3 compares the UV absorption spectrum of an undecylenic acid film before and after ozone treatment. The ozonolysis clearly produces a strong red-shift in the absorption spectrum presumably caused by the presence of aldehyde and peroxy groups in the oxidized sample. Ozonolysis of undecylenic acid in a nonparticipating solvent $\left(\mathrm{CH}_{2}-\right.$ $\mathrm{Cl}_{2}$ ) has a similar effect on its absorption spectrum (Figure 3). Note that the characteristic $290 \mathrm{~nm}$ band of the - CHO group is not visible suggesting that the absorption of the oxidized undecylenic acid is dominated by peroxy groups (see below).

Gas-Phase Products of Ozonolysis of Undecylenic Acid. In agreement with previous studies of ozonolysis of liquid terminal alkenes, ${ }^{39,41,42,71}$ the IR CRDS spectra taken during ozonolysis of pure undecylenic acid films detect formaldehyde as the major volatile product. Figure 4 shows a typical CRDS spectrum obtained during ozonolysis of the film in the 2800$3100 \mathrm{~cm}^{-1}$ window. The lines appear on a slowly changing background determined by the CRDS mirror reflectivity (the largest reflectivity and the longest ring-down time are achieved at $3000 \mathrm{~cm}^{-1}$ ). The majority of the lines can be assigned to rovibrational transitions of formaldehyde by an explicit com-

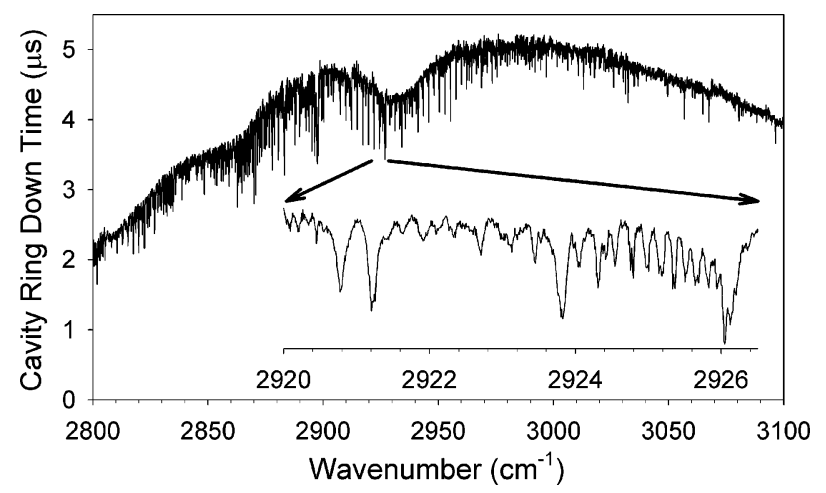

Figure 4. CRDS spectrum of the gas-phase oxidation products of undecylenic acid. The fine structure is due to formaldehyde, and the overall shape of the spectrum is due to the reflectivity profile of the cavity mirrors. Present experiments use the narrow window between 2920 and $2927 \mathrm{~cm}^{-1}$ showed in the enlarged region.

parison with its reference spectrum. Formic acid is also detected but in smaller amounts; the measured $[\mathrm{HCOOH}] /\left[\mathrm{H}_{2} \mathrm{CO}\right]$ branching ratio is $0.25 \pm 0.15$. These observations are in good agreement with those of refs 39 and 42, who detected little $\mathrm{HCOOH}$ in the ozonolysis of long-chain terminal alkenes.

A search for spectral signatures of the simplest Criegee intermediate, $\mathrm{H}_{2} \mathrm{C} \cdot \mathrm{OO} \cdot$, and the simplest dioxirane, $\mathrm{H}_{2} \mathrm{CO}_{2}$, was also attempted. Band-contour simulations predict that $\mathrm{CH}$ stretching bands of $\mathrm{H}_{2} \mathrm{C} \cdot \mathrm{OO} \cdot$ and $\mathrm{H}_{2} \mathrm{CO}_{2}$ should be easily distinguishable from those of $\mathrm{H}_{2} \mathrm{CO}$ at the $0.1 \mathrm{~cm}^{-1}$ spectral resolution. Furthermore, fairly accurate $\mathrm{CH}$-stretching frequencies are available for both species from theoretical calculations. ${ }^{79-82}$ Despite an extensive search, no $\mathrm{CH}$-stretching bands corresponding to $\mathrm{H}_{2} \mathrm{C} \cdot \mathrm{OO} \cdot$ and $\mathrm{H}_{2} \mathrm{CO}_{2}$ were found. This suggests that $\mathrm{H}_{2} \mathrm{C} \cdot \mathrm{OO} \cdot$ rapidly isomerizes into $\mathrm{HCOOH}$, reacts to form secondary ozonides and hydroxyhydroperoxides, or decomposes before it can escape from the film. This conclusion is supported by the analysis of the reaction products remaining in the condensed phase (see below). Even if $\mathrm{H}_{2} \mathrm{C} \cdot \mathrm{OO} \cdot$ does escape to the gas phase, it may be too short lived to be detected by IR CRDS under present conditions. ${ }^{53,54}$

Gas-Phase Products of Photolysis of Oxidized Undecylenic Acid. Unlike unoxidized undecylenic acid, which shows no measurable photodissociation activity, the oxidized film releases formic acid as the primary and $\mathrm{H}_{2} \mathrm{CO}$ as the secondary volatile product upon UV photolysis. Both products can be sensitively and unambiguously detected by IR CRDS via their highly structured IR absorptions. Figure 5 shows small sections of the CRDS spectra in the vicinity of $2920 \mathrm{~cm}^{-1}$. Explicit comparison of the CRDS spectra with reference spectra clearly shows that formic acid is the dominant product of photolysis of the oxidized film. More rigorous determination of the branching ratio using absolute absorption cross sections from the Northwest Infrared library $^{83}$ leads to the following result for $\lambda>290 \mathrm{~nm}$ photolysis: $[\mathrm{HCOOH}] /\left[\mathrm{H}_{2} \mathrm{CO}\right]=2.5 \pm 1.0$. Although this ratio depends on the extent of oxidation of the film and the extent of photolysis, $\mathrm{HCOOH}$ remains the dominant observed product under all conditions.

Note that the present CRDS instrument is blind to molecules with no $\mathrm{CH}$-stretching vibrations and the possible gas-phase photolysis products are not necessarily limited to $\mathrm{H}_{2} \mathrm{CO}$ and $\mathrm{HCOOH}$. We have attempted to detect other expected gas-phase products of ozonolysis (e.g., $\mathrm{H}_{2} \mathrm{O}, \mathrm{CO}$, and $\mathrm{CO}_{2}$ ) with an electron-impact mass spectrometer but ran into difficulties with the high background signal for these molecules. However, the mass-spectroscopic analysis of the film does contain very clear 

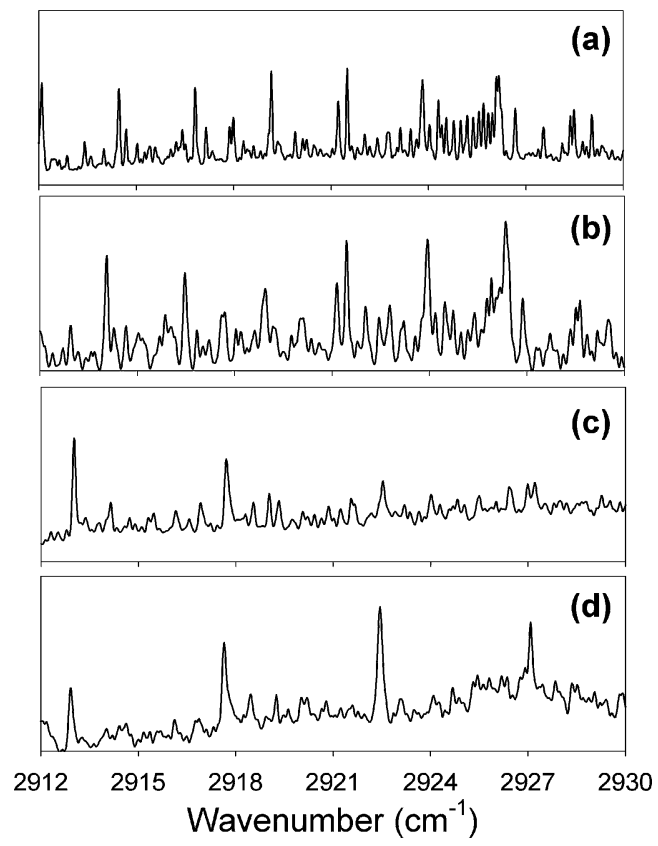

Figure 5. CRDS spectra taken during ozonolysis and subsequent photolysis of undecylenic acid: (a) reference spectrum of formaldehyde convoluted to the CRDS laser line width; (b) CRDS spectrum taken during the ozonolysis; (c) CRDS spectrum taken during UV photolysis of oxidized undecylenic acid; (d) reference optoacoustic spectrum of formic acid taken in parallel with CRDS.

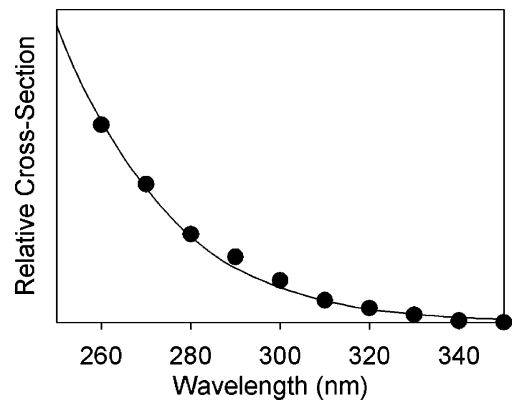

Figure 6. Comparison of action photodissociation (filled circles) and absorption (solid line) spectra of oxidized undecylenic acid. The action spectrum was arbitrarily scaled to fit the absorption data.

signatures of loss of $\mathrm{CO}(28 \mathrm{amu}), \mathrm{H}_{2} \mathrm{O}$ (18 amu), $\mathrm{HCOOH}$ (46 amu), and formaldehyde (30 amu) induced by UV photolysis.

Additional information about the photochemistry of freshly oxidized undecylenic acid can be obtained from an action photodissociation spectrum measured by monitoring the appearance of a specific photolysis product as a function of the UV wavelength. Figure 6 shows an action spectrum for the $\mathrm{HCOOH}$ formation channel obtained in pure nitrogen flow. The data in Figure 6 are obtained by fixing the IR CRDS laser on a chosen absorption line of $\mathrm{HCOOH}$ and scanning the monochromator in the UV illuminator in the range of 260-350 nm. The CRDS signal is converted into absorption coefficient and normalized with respect to the UV radiation power transmitted through the sample cell. The photolysis-induced signal is easily detectable even at $350 \mathrm{~nm}$, i.e., quite far into the tropospheric actinic window. The shape of the photodissociation spectrum is almost identical to the UV direct absorption spectrum of the oxidized undecylenic acid (Figure 3) suggesting that $\mathrm{HCOOH}$ must be a product of photolysis of one of the primary absorbers in the film.

Condensed-Phase Products of Ozonolysis/Photolysis of Undecylenic Acid. The oxidized undecylenic acid is analyzed

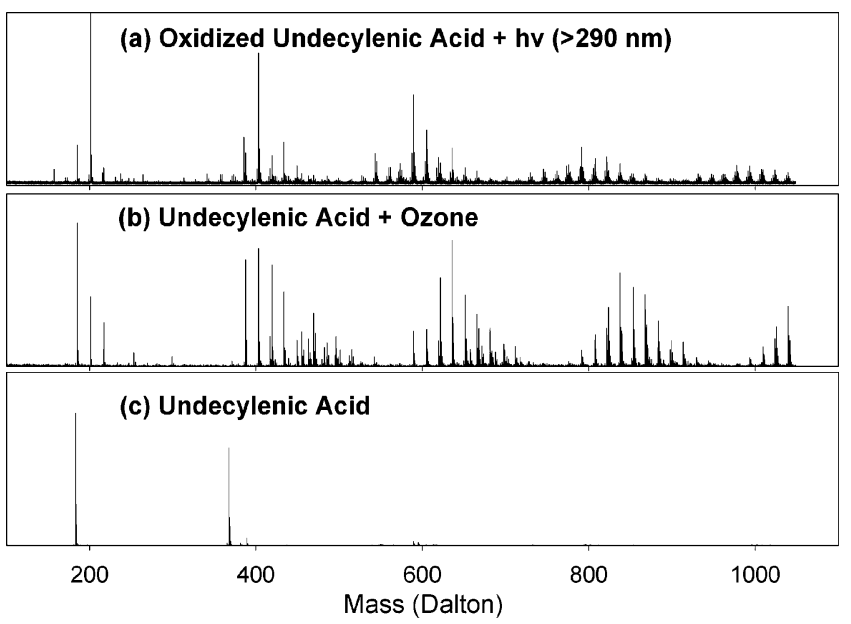

Figure 7. Negative ion electrospray mass-spectra of: (a) undecylenic acid film subjected to ozonolysis and then to photolysis $(\lambda>295 \mathrm{~nm})$ in dry air; (b) oxidized undecylenic acid; (c) pure undecylenic acid.

by electrospray ionization mass spectrometry in both positive and negative ion modes. In both cases, methanol is used as the solvent. The negative ion mode is particularly useful because nearly every product of ozonolysis of undecylenic acid contains at least one $-\mathrm{COOH}$ group. Therefore, the major peaks correspond to $-\mathrm{COO}^{-}$anions appearing in the $(\mathrm{M}-1)$ channels with minimal fragmentation and polymerization. Figure 7 shows a sample negative ion mass spectrum of pure undecylenic acid $(\mathrm{MW}=184 \mathrm{amu})$. The spectrum is clearly dominated by a single peak at $183 \mathrm{amu}$. The second largest peak, which appears only if an overconcentrated solution of undecylenic acid is injected, corresponds to a complex between undecylenic acid monomer and its anion ( $\mathrm{MW}=367 \mathrm{amu}$ ). Larger complexes do not appear in the mass spectrum under present experimental conditions. The positive ion mode spectra are somewhat more complicated but still assignable. The primary peaks correspond to complexes of a parent molecule with $\mathrm{Na}^{+}$ion $(\mathrm{M}+23)$ and, in the case of carboxylic acids, complexes of a $\mathrm{Na}$ salt of a parent acid with another $\mathrm{Na}^{+}$ion $(\mathrm{M}+45)$.

The oxidized films were dissolved in the same volume of methanol as the volume used for the undecylenic acid reference spectrum (Figure 7). The resulting spectrum contains many peaks corresponding to previously identified products. For example, sebacic acid, $\mathrm{HOOC}-\left(\mathrm{CH}_{2}\right)_{8}-\mathrm{COOH}$, and sebaldehydic acid, $\mathrm{HOOC}-\left(\mathrm{CH}_{2}\right)_{8}-\mathrm{COH}$, are reproducibly observed in comparable amounts in the mass spectrum. Both acids are expected products of decomposition of the primary ozonide of undecylenic acid (Figure 8). However, nonanoic acid is not an observed product as found in a previous study of ozonolysis of undecylenic acid. ${ }^{42}$ No significant signal corresponding to the SOZ of undecylenic acid was observed; it is likely to be destroyed by the high temperature of the ion source. Table 1 summarizes the observed peak positions and proposed assignments for the mass spectra of products of ozonolysis of undecylenic acid films. Ozone + multilayered film of undecylenic acid and ozone + undecylenic acid dissolved in a nonparticipating solvent resulted in a similar set of observed products.

In addition to the known low molecular weight products of ozonolysis of undecylenic acid, many previously unidentified oligomeric products are also observed. For example, the mass spectrum shown in Figure 7 has several well-defined "clusters" of peaks between 300 and 1000 amu. This mass spectrum corresponds to a strongly oxidized sample with almost no remaining undecylenic acid, but we observe similar clusters of 


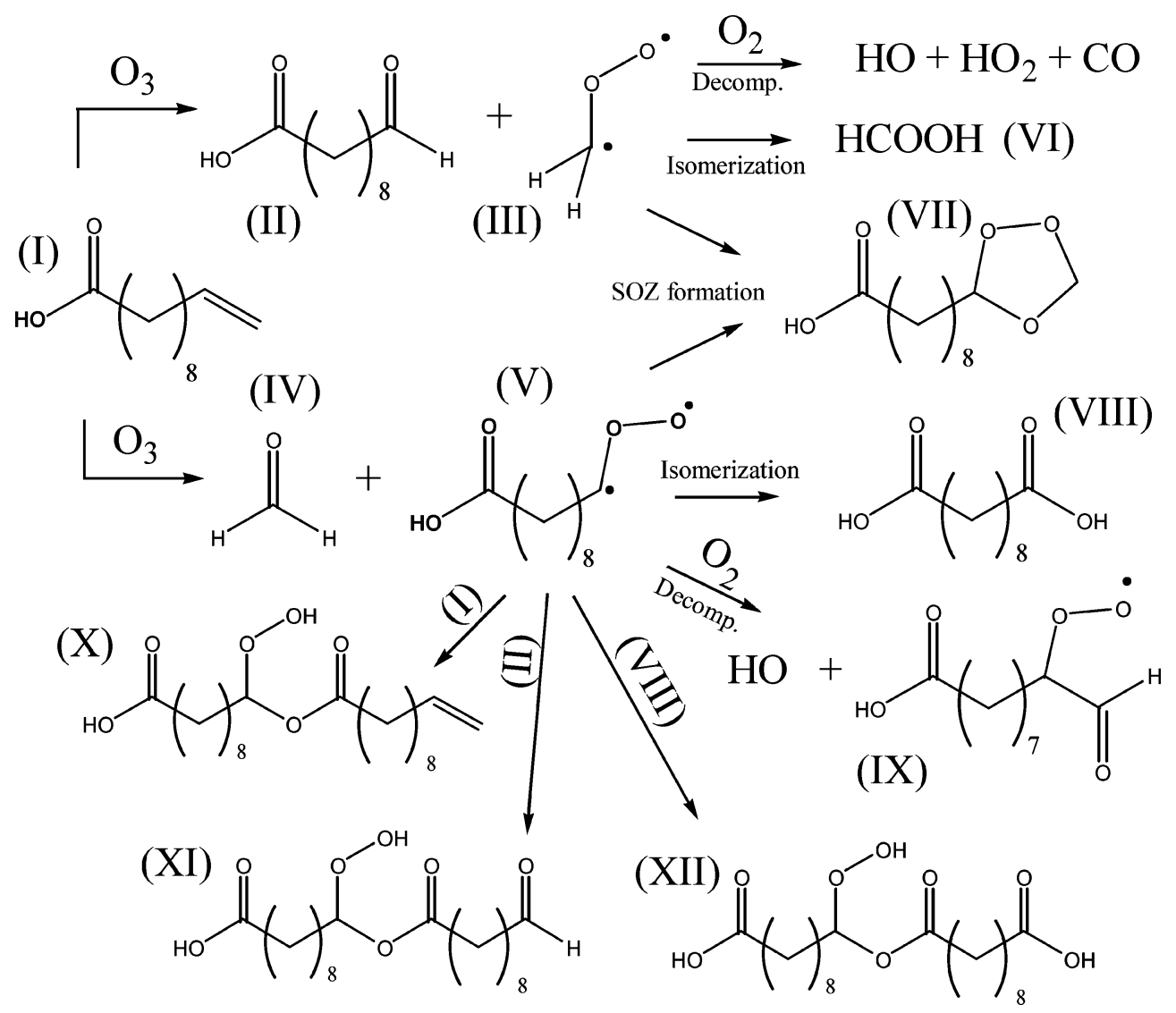

Figure 8. Primary reactions taking place during ozonolysis of undecylenic acid film. Products (II, IV, VI, VIII, X, XI, XII) could be observed directly. SOZ (VII) and carbonyl oxides (III, V) participate in secondary reactions such as decomposition and oligomerization (not shown).

TABLE 1: List of Assigned Peaks in the Negative-Ion Electrospray Mass Spectrum of Oxidized Undecylenic Acid ${ }^{a}$

\begin{tabular}{lrrrrr}
\hline & $\mathrm{M}-1$ & $\begin{array}{c}\mathrm{M}-1 \\
+\mathrm{O}_{2}\end{array}$ & $\begin{array}{c}\mathrm{M}-1 \\
+2 \mathrm{O}_{2}\end{array}$ & $\begin{array}{c}\mathrm{M}-1 \\
+3 \mathrm{O}_{2}\end{array}$ & $\begin{array}{c}\mathrm{M}-1 \\
+4 \mathrm{O}_{2}\end{array}$ \\
\hline undecylenic acid (I) & 183.2 & 215.2 & 247.2 & 279.2 & 311.4 \\
(I + V $\equiv$ X) & 385.3 & 417.3 & 449.3 & 481.3 & \\
(I + 2V) & 587.4 & 619.4 & 651.4 & 683.4 & \\
(I + 3V) & 789.5 & 821.5 & 853.5 & 885.5 & \\
(I + 4V) & 991.6 & & & & \\
sebaldehydic acid (II) & 185.1 & 217.1 & & & \\
(II + V = XI) & 387.3 & 419.3 & & & \\
(II + 2V) & 589.4 & 621.4 & & & \\
(II + 3V) & 791.5 & 823.5 & & & \\
(II + 4V) & 993.6 & & & & \\
sebacic acid (VIII) & 201.2 & 233.2 & 265.2 & 297.2 & \\
(VIII + V $\equiv$ XII) & 403.3 & 435.3 & 467.3 & 499.3 & 531.3 \\
(VIII + 2V) & 605.5 & 637.5 & 669.5 & 701.5 & 733.5 \\
(VIII + 3V) & 809.6 & 841.6 & 873.6 & 905.6 & 937.6
\end{tabular}

${ }^{a}$ Approximately $50 \%$ of the primary-isotope peaks with intensities above $10 \%$ of the maximum are assignable. All peaks are detected in the $\mathrm{M}-1$ channel corresponding to deprotonation of $-\mathrm{COOH}$ groups. Roman numerals for organic molecules are defined in Figure 8.

peaks in mass spectra with a lower degree of oxidation. The most prominent peaks within each cluster are separated by the mass of an oxygen atom (16 amu). The clusters themselves are separated from each other by the mass of the larger carbonyl oxide formed in the decomposition of the primary ozonide of undecylenic acid (202 amu). This pattern of peaks can be interpreted as a result of various polymerization reactions taking place during the ozonolysis. The upper limit for the mass spectrum is $1000 \mathrm{amu}$, and the largest observed cluster of peaks corresponds to a "pentamer". However, on the basis of the peak intensity distribution in the mass spectrum, even larger oligomers are likely to be present in the oxidized film. The chemical identity of some of these oligomers will be discussed below.

The presence of oligomers in an analyte can sometimes be confused with an excessive complex formation in the electrospray ion source. The latter possibility can be ruled out based on: (i) the lack of oligomers (other than the dimer) in the reference spectrum of undecylenic acid obtained under the same conditions; (ii) reproducible presence of oligomer peaks in the mass spectrum irrespective of the concentration of the oxidized sample in the solvent; (iii) appearance of the same oligomers in both negative ion $(\mathrm{M}-1)$ and positive ion $(\mathrm{M}+23, \mathrm{M}+$ 45) mass spectra.

The products of the UV photolysis of the oxidized film were also examined. The photolysis was carried out with a $290 \mathrm{~nm}$ long-pass filter in dry air at atmospheric pressure. Figure 7 displays a sample mass spectrum. The UV exposure clearly has several reproducible effects on the spectrum. The peaks corresponding to molecules containing aldehyde and peroxy groups are reduced in intensity. For example, the intensity of the sebaldehydic acid peak is considerably reduced relative to that of sebacic acid. The oligomeric clusters of peaks survive the UV exposure, but they are clearly shifted to somewhat lower masses. The observed UV-induced fragmentation corresponds to the loss of $\mathrm{CO}(-28 \mathrm{amu}), \mathrm{H}_{2} \mathrm{O}(-18 \mathrm{amu}), \mathrm{HCOOH}(-46$ $\mathrm{amu})$, and formaldehyde $(-30 \mathrm{amu})$. Only a small fraction of peaks can be assigned to specific molecules.

Iodometric Test for the Presence of Peroxides. An iodometric test ${ }^{84}$ was carried out in an attempt to quantify the number of peroxy bonds formed in the oxidized undecylenic acid per number of reacted ozone molecules. Undecylenic acid was dissolved in a nonparticipating solvent (hexadecane) to make a $2.0 \mathrm{mM}$ solution, and a $10 \%$ molar equivalent of ozone was 
bubbled through the solution at room temperature. The resulting solution was thoroughly degassed with dry nitrogen to remove any dissolved oxygen. A fraction of the solution was added to a degassed mixture of chloroform, acetic acid, and water containing an excess amount (relative to that of undecylenic acid) of KI. The aqueous fraction was separated and analyzed with UV/Vis spectrometry. As every peroxy bond produces one $\mathrm{I}_{3}{ }^{-}$by oxidation of $2 \mathrm{I}^{-}$to $\mathrm{I}_{2}$ followed by complexation of $\mathrm{I}_{2}$ with $\mathrm{I}^{-}$in the presence of acids, measured absorbance of $\mathrm{I}_{3}{ }^{-}$ (using $\epsilon_{470 \mathrm{~nm}}=817 \mathrm{~L} \mathrm{~mol}^{-1} \mathrm{~cm}^{-1}$ ) 84 is directly related to the concentration of peroxy bonds. A calibration experiment using $\mathrm{H}_{2} \mathrm{O}_{2}$ reproduced the $\mathrm{H}_{2} \mathrm{O}_{2}$ concentration with better than $10 \%$ accuracy, with one molar equivalent of peroxy bonds producing one molar equivalent of $\mathrm{I}_{3}{ }^{-}$.

Quantification of peroxy groups in the oxidized undecylenic acid was complicated by poor solubility of the oxidation products in the chloroform/acetic acid/water mixture. Depending on the reaction conditions, the results ranged from 0.2 to more than 1.0 peroxide groups in the oxidation products per molecule of ozone bubbled through the solution. This is qualitatively consistent with the mass-spectrometric results, which show that the majority of the oxidation products have hydroperoxy functionalities.

\section{Discussion}

Mechanism of Ozonolysis of Undecylenic Acid. The major gas- and liquid-phase products of ozonolysis of undecylenic acid are generally consistent with the Criegee mechanism of ozonolysis of alkenes. ${ }^{47}$ Figure 8 shows the most important initial reactions taking place in this system. The initial ozone attack on the double bond of undecylenic acid (I) results in a highly unstable POZ (not shown). POZ rapidly decomposes into two sets of products: sebaldehydic acid (II) and a small carbonyl oxide (III); formaldehyde (IV) and a large carbonyl oxide (V). Formic (VI) and sebacic (VIII) acids are produced by isomerization of the corresponding carbonyl oxides. SOZ (VII) is produced by recombination of fragments of $\mathrm{POZ}$ decomposition; production of SOZ is known to be efficient in liquids. Apart from SOZ, all of the stable products shown in Figure 8 are directly observed by mass spectrometry and/or CRDS in this work.

The excess of gas-phase formaldehyde over formic acid is consistent with previous work on ozonolysis of multilayered films and SAM of terminal alkenes. ${ }^{39,41,42,71}$ It is likely that the initial splitting of POZ occurs with nearly equal probability for the formaldehyde and sebaldehydic acid channels. Indeed, (II) and (VIII) are generated in comparable amounts in the oxidized film. However, not all of the carbonyl oxide (III) will isomerize into formic acid; the ratio measured here, $\mathrm{HCOOH} / \mathrm{H}_{2} \mathrm{CO}=$ $0.25 \pm 0.15$, is considerably below unity.

Polymers were recently observed in chamber studies of the oxidation of organic aerosol particles. ${ }^{85-89}$ The chemistry responsible for polymerization was attributed to acid-catalyzed aldol and gem-diol condensation. In the present case, the polymerization mechanism is entirely different. Indeed, many oligomeric compounds observed in the mass spectrum can be assigned as products of reactions of carbonyl oxides with the carboxylic groups in undecylenic acid and in the ozonolysis products.<smiles>[R]CO[O]</smiles>

The mass spectrum in Figure 7 contains sizable peaks corresponding to "dimeric" structures (X, XI, XII) resulting from condensation of carbonyl oxide (V) with undecylenic, sebaldehydic, and sebacic acids, respectively (Figure 8). In addition, there are peaks with larger masses corresponding to further additions of carbonyl oxide (V) to (X, XI, XII) and to larger oligomers. The largest detected oligomers correspond to "pentamers". Even larger oligomers probably exist in the oxidized mixture, but they fall outside the mass range of the mass spectrometer. Surprisingly, there is no evidence of the smaller carbonyl oxide (III) addition to undecylenic acid and/or other molecules. Therefore, we presume that the dominant reaction pathways for (III) are decomposition and isomerization to formic acid.

It was suggested ${ }^{67}$ that carbonyl oxides can also add to double bonds in unsaturated fatty acids to form peroxidic five-member rings:

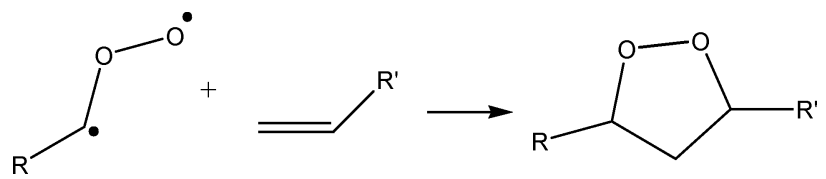

The mass-spectrometer would not be able to differentiate between the products of addition of a carbonyl oxide to the carboxylic or alkene groups of undecylenic acid because such products would have identical molecular weights. However, if the chemistry was dominated by the double bond addition, the extensive polymerization would not take place as the reaction would terminate at the "dimer" level. On the contrary, addition to the carboxylic end of undecylenic acid can be propagated further as it leaves a double bond in the product ready for the next cycle of ozonolysis + polymerization. The observed distribution of oligomers in the mass spectrum shown in Figure 7 suggests that reaction of carbonyl oxides with the carboxylic groups is the dominant polymerization route.

The small $\mathrm{HCOOH} / \mathrm{HCHO}$ ratio and absence of condensation reaction products for carbonyl oxide (III) imply that its decomposition into $\mathrm{HCO}$ and $\mathrm{OH}$ radicals may be quite efficient ( $\mathrm{HCO}$ then quickly reacts with oxygen to produce $\mathrm{HO}_{2}$ and $\mathrm{CO}$ ). A fraction of carbonyl oxide (V) can also decompose to produce $\mathrm{OH}$ and peroxy radical (IX). Such decomposition reactions are known to play an important role in gas-phase alkene ozonolysis, ${ }^{49-51,90,91}$ results of this work suggest that such decomposition may also take place in the liquid phase. Once $\mathrm{OH}$ is generated, it can either add to the double bond in undecylenic acid or abstract a hydrogen atom from one of the neighboring $\mathrm{CH}_{2}$ groups. Figure 9 shows an example of a reaction sequence initiated by $\mathrm{OH}$ addition to undecylenic acid. This sequence ultimately generates peroxy groups via $\mathrm{RO}_{2}+\mathrm{HO}_{2}$ reactions, but it is also capable of installing multiple oxygen atoms in the molecules via $\mathrm{RO}_{2}+\mathrm{R}^{\prime} \mathrm{O}_{2}$ reactions, followed by facile isomerization of the resulting alkyloxy radicals, followed by addition of $\mathrm{O}_{2}$. Note that an abstraction of a hydrogen atom by $\mathrm{OH}$ would initiate a similar chain of events.

The insertion of multiple oxygen atoms into the various reaction products is clearly evident from the mass spectrum (Figure 7). Indeed, there are several families of peaks in the mass spectrum separated from each other by either 16 or 32 atomic mass units. Table 1 represents an attempt to tie the major peaks to common precursor molecules through a sequence of $+n \mathrm{O}_{2}$ additions. Such a representation accounts for nearly half of the products formed during ozonolysis. The peaks that could not be assigned to specific structures also appear in families separated by 16 and/or 32 atomic mass units. One could generate 


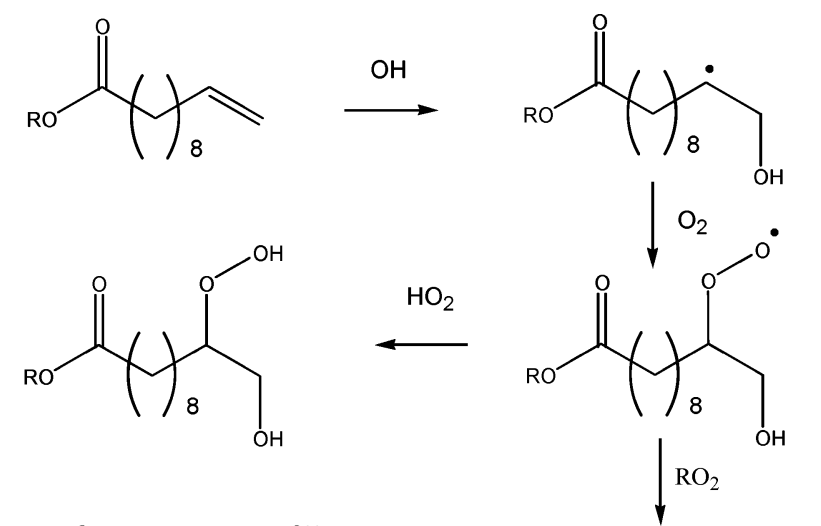<smiles>[R6]C(=O)C(C)(C)C(C)(C)C(C)(C)C(C)(C)C(C)(C)C(O)CO</smiles>

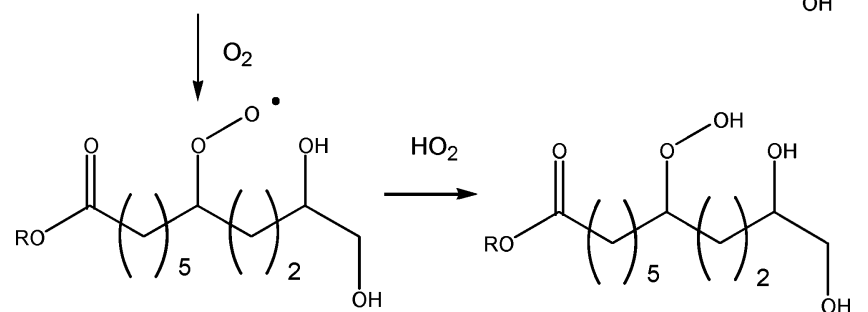
$\downarrow \mathrm{RO}_{2} \quad$ and so on ...

Figure 9. Proposed mechanism for the formation of additional peroxy bonds in the oxidized sample. $\mathrm{OH}$ and $\mathrm{HO}_{2}$ come from decomposition of carbonyl oxide (III).

a similar table assuming single O (16 amu) additions (Figure 9). However, the aldehyde-terminated and carboxylic acidterminated products differ by one $\mathrm{O}$ atom leading to overlapping series. Mass-spectrometry would not be able to distinguish the series resulting from single- $\mathrm{O}$ and double-O additions in this particular case.

As the oligomer size grows from monomer to pentamer, the propensity for $\mathrm{O}_{2}$ insertions increases. In fact, the intensity of $\mathrm{M}+\mathrm{O}_{2}$ peaks relative to that of $\mathrm{M}$ peaks grows approximately proportionally to the size of $\mathrm{M}$ ( $\mathrm{M}$ stands for any molecule). For example, the $\left[\mathrm{M}+\mathrm{O}_{2}\right] /[\mathrm{M}]$ ratio is $0.3,1.2,2.4,3.4$, and 4.0 for $\mathrm{M}=$ sebaldehydic acid $+0,1,2,3$, and 4 units of carbonyl oxide (V), respectively. This observation is fully consistent with the increase in available reactive sites for the $\mathrm{OH}$ attacks.

Mechanism of Photolysis. $\mathrm{HCOOH}$ and $\mathrm{HCHO}$ can be easily observed in the photolysis of oxidized undecylenic acid (Figure 5). This is a curious observation as neither sebacic acid (VIII) nor sebaldehydic acid (II) can directly photolyze into $\mathrm{HCOOH}$ and $\mathrm{HCHO}$ under the mild UV excitation conditions of the present work. Norrish type II splitting of sebaldehydic acid would produce the enol corresponding to acetaldehyde, $\mathrm{CH}_{2}=$ $\mathrm{CH}-\mathrm{OH}$, and $\alpha$-cleavage of sebaldehydic acid would yield $\mathrm{HCO}$ or CO. These processes do occur but neither of them can account for formic acid being the primary photolysis product.

Because of the complexity of the oxidized film, it is not trivial to assign a specific precursor responsible for the photoinduced release of these two molecules. However, close similarity between the action spectrum and absorption spectrum of oxidized undecylenic acid (Figure 6), the characteristic shape of the action spectrum, and the large amount of peroxy bonds measured by the iodometric test suggest that photochemistry
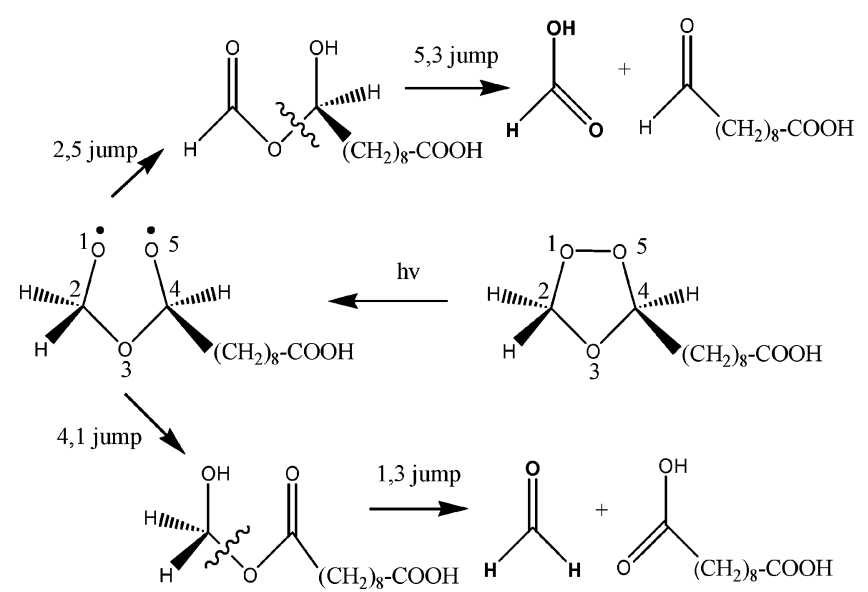

Figure 10. One of the possible mechanisms of photolytic production of $\mathrm{HCHO}$ and $\mathrm{HCOOH}$ from the oxidized undecylenic acid. Preferential formation of $\mathrm{HCOOH}$ can be explained by steric hindrance in the H-transfer step.

must be initiated by splitting one of the $-\mathrm{O}-\mathrm{O}-$ bonds. One possibility would be photolysis of hydroxylhydroperoxides such as $(\mathrm{X}, \mathrm{XI}, \mathrm{XII})$ releasing $\mathrm{OH}$, with secondary reactions of $\mathrm{OH}$ with oligomeric ozonolysis reaction products producing $\mathrm{HCOOH}$ and $\mathrm{HCHO}$.

Another possible precursor of both $\mathrm{HCHO}$ and $\mathrm{HCOOH}$ is terminal SOZ such as (VII). Previous research on ozonides suggest that UV photolysis must break the weakest $-\mathrm{O}-\mathrm{O}-$ bond, with subsequent isomerization processes resulting in release of an aldehyde or carboxylic acid in the gas phase. ${ }^{47,92,93}$ Such a mechanism can explain the preferred formation of formic acid relative to formaldehyde in the photolysis: the pathway leading to $\mathrm{HCOOH}$ is less sterically hindered (Figure 10). The high stability of SOZs is not unprecedented; SOZ obtained by ozonolysis of 2,3-dimethyl-butene remains stable for days in solutions ${ }^{94}$ and for hours in the gas phase $\mathrm{e}^{95}$ at room temperature. We do not observe large peaks corresponding to (VII) and larger secondary ozonides in the mass spectrum. However, it is possible that SOZ of undecylenic acid is not as stable as heavily substituted SOZ of 2,3-dimethyl-butene, and it decomposes into an aldehyde-acid pair under high-temperature conditions of the electrospray ion source.

Photolysis Products Remaining in the Film. The mass spectrum of oxidized undecylenic acid film changes considerably after photolysis (Figure 7). The most prominent change is the increase in relative intensity of the sebacic acid peak, because this is more or less the only product molecule that is resilient to photolysis under these conditions $(\lambda>290 \mathrm{~nm})$. On the contrary, all the peaks assigned to photochemically unstable aldehydes (e.g., II) and peroxides (X, XI, XII, etc.) are reduced in intensity.

The second most apparent change is the appearance of many new mass peaks in the mass spectrum (Figure 7). The mass spectrum still maintains the general periodic appearance of clusters of peaks, although the clusters are shifted toward smaller masses compared to the mass spectrum obtained before photolysis. In addition to peaks corresponding to loss of $\mathrm{HCOOH}$ and $\mathrm{HCHO}$, there are peaks corresponding to loss of $\mathrm{CO}$ resulting from photolysis of aldehydes, and loss of $\mathrm{H}_{2} \mathrm{O}$ resulting from photolysis of hydroxylhydroperoxides.<smiles>[R]C(=O)OC([R])=O</smiles> 
There is evidence for multiple losses of $\mathrm{H}_{2} \mathrm{O}$ from the same precursor molecules corresponding to the photolysis of products containing multiple hydroperoxy moieties.

Atmospheric Implications. Results of this work strongly suggest that UV photolysis in aerosol particle phase play a significant role in atmospheric processing of primary (POA) and secondary (SOA) organic aerosol particles. Indeed, a large fraction of POA in urban areas comes from cooking emissions, ${ }^{62,96}$ which contain unsaturated fatty acids, cholesterol, and other unsaturated organics. Reactions of these molecules with ozone and $\mathrm{OH}$ will make them photochemically active and open new pathways for aerosol particle photochemistry. Aerosol particle processing by solar radiation is also likely to be important for SOA generated by oxidation of terpenes. For example, a strong effect of UV radiation on the yield of SOA in terpene ozonolysis was reported in refs 97 and 98. The SOA yield is presumably reduced by the UV radiation because of the photolytic splitting of primary oxidation products into smaller, more volatile species. On the basis of the results of this work, photolysis of organic peroxides is the most likely reason for the observed effects of UV radiation on the SOA yields.

A rough estimate of the relative importance of photolysis in aging of organic aerosol particles can be made assuming typical urban concentrations, $[\mathrm{OH}]=10^{6} \mathrm{~cm}^{-3},\left[\mathrm{O}_{3}\right]=10^{12} \mathrm{~cm}^{-3}$, and using measured surface reaction probabilities for $\mathrm{OH}(\gamma>0.1$ on solid organic surfaces $)^{32}$ and $\mathrm{O}_{3}\left(\gamma>10^{-5}\right.$ on frozen surfaces of fatty acids). ${ }^{40}$ By use of oleic acid as a representative component of an organic aerosol particle, one can estimate the lifetime of double bonds with respect to the attack by $\mathrm{O}_{3}$ as $<10^{3} \mathrm{~s}$, and the lifetime of $-\mathrm{CH}_{2}-$ groups with respect to $\mathrm{OH}$ oxidation as $<10^{5} \mathrm{~s}$. The observed lifetime of oleic acid in multiphase aerosol particles is actually longer because the molecules are buried inside the particle. ${ }^{99}$ The carbonyl groups and peroxy groups appearing in the oxidation will have a photolysis lifetime around $3 \times 10^{4} \mathrm{~s}$ and $10^{5} \mathrm{~s}$, respectively (calculated for zero solar zenith angle, "best estimate" surface albedo, ${ }^{1}$ and absorption cross sections for acetaldehyde and hydrogen peroxide). ${ }^{100}$ Furthermore, the relative rate of photolysis will increase in the upper troposphere. For example, the lifetime of acetone, the most representative gas-phase ketone, is dominated by photolysis not by reaction with $\mathrm{OH}$, in the upper troposphere. ${ }^{1}$ Therefore, photolysis and $\mathrm{OH}$ oxidation may have comparable contributions to the rates of chemical transformations occurring in organic aerosol particles.

Although the results of this work are highly suggestive, they cannot be immediately applied to the actual atmosphere without resolving several limitations of the present approach. Dry oxidation conditions, unrealistically large ozone concentration, photolysis under low pressure in an oxygen and $\mathrm{NO}_{x}$ free environment, and use of a pure multilayered film instead of a multicomponent organic aerosol may distort the potential importance of photochemical processes discussed here in actual atmospheric aerosol particles. Our current experiments focus on resolving all these issues.

\section{Conclusions}

This work represents the first experimental inquiry into the role of solar radiation in atmospheric processing of organic aerosols. Although the molecule selected for this study (undecylenic acid) is not a common constituent of airborne particulate matter, ${ }^{60}$ the general conclusions of this work are likely to hold for all organic aerosol particles containing significant amounts of unsaturated organics:
1. Oxidation of unsaturated organic molecules in aerosol particles is expected to make them absorb radiation in the tropospheric actinic window $(\lambda>295 \mathrm{~nm})$. This prediction is explicitly verified in this work for the case of ozonolysis of terminal alkenes.

2. Photochemistry occurring in the oxidized aerosol particles is expected to contribute significantly to the atmospheric processing of organic aerosols. Furthermore, such photochemical processes may generate products that evaporate from the particle into the gas-phase. For the present case of ozonolysis or terminal alkenes, the observed gas-phase photolysis products are formaldehyde and formic acid.

3. Prolonged solar photolysis is likely to significantly affect the chemical composition of organic aerosol particles. For example, we observe a clear effect of UV post-treatment on the degree of polymerization and product distribution in the oxidized undecylenic acid.

In addition to the general conclusions, this work provides new information on the mechanistic details of ozonolysis of undecylenic acid. The most interesting observations include a large degree of oligomerization in the ozonolysis products caused by sequential additions of carboxyl oxides to $-\mathrm{COOH}$ groups, and a very large concentration of peroxy moieties in the oxidized products also mediated by carbonyl oxide reactions. Even for such a simple molecule, only a fraction of the final ozonolysis products could be assigned to specific chemical structures.

Acknowledgment. This study was supported by the National Science Foundation through the Environmental Molecular Science Institute program, Grant CHE-0431312, and the Atmospheric Chemistry Program, Grant ATM-0509248. Jiho Park was supported by the Camille and Henry Dreyfus Foundation via a Postdoctoral Scholarship in Environmental Chemistry. Maggie Walser was supported by the National Science Foundation Graduate Research Fellowship program.

Supporting Information Available: Lists of the mass peaks in negative ion ESI mass spectra of a sample obtained by ozonolysis of undecylenic acid film and a sample obtained by ozonolysis of undecylenic acid film followed by photolysis. This material is available free of charge via the Internet at http:// pubs.acs.org.

\section{References and Notes}

(1) Finlayson-Pitts, B. J.; Pitts, J. N. Chemistry of the Upper and Lower Atmosphere: Theory, Experiments, and Applications; Academic Press: 2000 .

(2) Seinfeld, J. H.; Pandis, S. N. Atmospheric Chemistry and Physics: From Air Pollution to Climate Change, 1998.

(3) Nathanson, G. M.; Davidovits, P.; Worsnop, D. R.; Kolb, C. E. J. Phys. Chem. 1996, 100, 13007.

(4) Garrett, B. C. Science 2004, 303, 1146.

(5) Reid, J. P.; Sayer, R. M. Chem. Soc. Rev. 2003, 32, 70.

(6) Mmereki, B. T.; Donaldson, D. J. J. Phys. Chem. A 2003, 107, 11038.

(7) Jungwirth, P.; Tobias, D. J. J. Phys. Chem. B 2002, 106, 6361.

(8) Knipping, E. M.; Lakin, M. J.; Foster, K. L.; Jungwirth, P.; Tobias, D. J.; Gerber, R. B.; Dabdub, D.; Finlayson-Pitts, B. J. Science 2000, 288, 301.

(9) Abbatt, J. P. D. Chem. Rev. 2003, 103, 4783.

(10) Liu, D.; Ma, G.; Levering, L. M.; Allen, H. C. J. Phys. Chem. B 2004, 108, 2252.

(11) Usher, C. R.; Michel, A. E.; Grassian, V. H. Chem. Rev. 2003, $103,4883$.

(12) Broekhuizen, K.; Kumar, P. P.; Abbatt, J. P. D. Geophys. Res. Lett. 2004, 31, L01107/1.

(13) Petersen, P. B.; Saykally, R. J. Chem. Phys. Lett. 2004, 397, 51.

(14) Alves, C.; Carvalho, A.; Pio, C. J. Geophys. Res. 2002, 107, ICC7/ 
(15) Alves, C.; Pio, C.; Duarte, A. Atmos. Environ. 2001, 35, 5485.

(16) Duce, R. A.; Mohnen, V. A.; Zimmerman, P. R.; Grosjean, D.; Cautreels, W.; Chatfield, R.; Jaenicke, R.; Ogren, J. A.; Pellizzari, E. D.; Wallace, G. T. Rev. Geophys. Space Phys. 1983, 21, 921.

(17) Jacobson, M. C.; Hansson, H. C.; Noone, K. J.; Charlson, R. J. Rev. Geophys. 2000, 38, 267.

(18) Hildemann, L. M.; Markowski, G. R.; Cass, G. R. Environ. Sci. Technol. 1991, 25, 744 .

(19) Liu, D.-Y.; Wenzel, R. J.; Prather, K. A. J. Geophys. Res. 2003 , 108 , SOS $14 / 1$

(20) Middlebrook, A. M.; Murphy, D. M.; Thomson, D. S. J. Geophys. Res. 1998, 103, 16475.

(21) Mochida, M.; Kitamori, Y.; Kawamura, K.; Nojiri, Y.; Suzuki, K. J. Geophys. Res. 2002, 107, AAC1/1.

(22) Murphy, D. M.; Thomson, D. S.; Mahoney, M. J. Science 1998, 282,1664

(23) Raes, F.; Bates, T.; McGovern, F.; Van Liedekerke, M. Tellus, Ser. $B$ 2000, $52 B, 111$.

(24) Falkovich, A. H.; Schkolnik, G.; Ganor, E.; Rudich, Y. J. Geophys. Res. 2004, 109, D02208/1.

(25) Diamond, M. L.; Gingrich, S. E.; McCarry, B. E.; Stern, G. A.; Tomy, G. Organohalogen Compounds 1999, 41, 343.

(26) Tervahattu, H.; Juhanoja, J.; Kupiainen, K. J. Geophys. Res. 2002, 107, ACH18/1.

(27) Tervahattu, H.; Hartonen, K.; Kerminen, V.-M.; Kupiainen, K.; Aarnio, P.; Koskentalo, T.; Tuck, A. F.; Vaida, V. J. Geophys. Res. 2002, 107, AAC $1 / 1$

(28) Gill, P. S.; Graedel, T. E.; Weschler, C. J. Rev. Geophys. Space Phys. 1983, 21, 903.

(29) Donaldson, D. J.; Anderson, D. J. Phys. Chem. A 1999, 103, 871.

(30) Rudich, Y. Chem. Rev. 2003, 103, 5097.

(31) Ellison, G. B.; Tuck, A. F.; Vaida, V. J. Geophys. Res. 1999, 104 11633.

(32) Bertram, A. K.; Ivanov, A. V.; Hunter, M.; Molina, L. T.; Molina,

M. J. J. Phys. Chem. A 2001, 105, 9415.

(33) Zhou, X.; Gao, H.; He, Y.; Huang, G.; Bertman, S. B.; Civerolo,

K.; Schwab, J. Geophys. Res. Lett. 2003, 30, ASC 12/1.

(34) Zhou, X.; He, Y.; Huang, G.; Thornberry, T. D.; Carroll, M. A.; Bertman, S. B. Geophys. Res. Lett. 2002, 29, 26/1.

(35) Sumner, A. L.; Shepson, P. B. Nature 1999, 398, 230.

(36) Guimbaud, C.; Grannas, A. M.; Shepson, P. B.; Fuentes, J. D.;

Boudries, H.; Bottenheim, J. W.; Domine, F.; Houdier, S.; Perrier, S.;

Biesenthal, T. B.; Splawn, B. G. Atmos. Environ. 2002, 36, 2743.

(37) Domine, F.; Shepson, P. B. Science 2002, 297, 1506.

(38) Zhou, X.; Beine, H. J.; Honrath, R. E.; Fuentes, J. D.; Simpson,

W.; Shepson, P. B.; Bottenheim, J. W. Geophys. Res. Lett. 2001, 28, 4087.

(39) Thomas, E. R.; Frost, G. J.; Rudich, Y. J. Geophys. Res. 2001 106,3045 .

(40) Moise, T.; Rudich, Y. J. Phys. Chem. A 2002, 106, 6469.

(41) Moise, T.; Rudich, Y. J. Geophys. Res. 2000, 105, 14667.

(42) Eliason, T. L.; Aloisio, S.; Donaldson, D. J.; Cziczo, D. J.; Vaida, V. Atmos. Environ. 2003, 37, 2207.

(43) Smith, G.; Hauser, C.; Baer, T.; Miller, R. E.; Woods, E., III. Abstr. Pap. Am. Chem. Soc. 2001, HYS.

(44) Morris, J. W.; Davidovits, P.; Jayne, J. T.; Jimenez, J. L.; Shi, Q.; Kolb, C. E.; Worsnop, D. R.; Barney, W. S.; Cass, G. Geophys. Res. Lett. 2002, 29, 71/1.

(45) Wadia, Y.; Tobias, D. J.; Stafford, R.; Finlayson-Pitts, B. J. Langmuir 2000, 16, 9321. 4637.

(46) Lai, C. C.; Yang, S. H.; Finlayson-Pitts, B. J. Langmuir 1994, 10 ,

(47) Bailey, P. S. Organic Chemistry, Vol. 39, Pt. 1: Ozonation in Organic Chemistry, Vol. 1: Olefinic Compounds; Academic Press: 1978.

(48) Criegee, R. Angew. Chem. 1975, 87, 765.

(49) Rickard, A. R.; Johnson, D.; McGill, C. D.; Marston, G. J. Phys. Chem. A 1999, 103, 7656.

(50) Horie, O.; Moortgat, G. K. Atmos. Environ. A 1991, 25A, 1881.

(51) Paulson, S. E.; Chung, M. Y.; Hasson, A. S. J. Phys. Chem. A 1999, 103,8125 .

(52) Kroll, J. H.; Donahue, N. M.; Cee, V. J.; Demerjian, K. L.; Anderson, J. G. J. Am. Chem. Soc. 2002, 124, 8518.

(53) Kroll, J. H.; Clarke, J. S.; Donahue, N. M.; Anderson, J. G.; Demerjian, K. L. J. Phys. Chem. A 2001, 105, 1554

(54) Kroll, J. H.; Sahay, S. R.; Anderson, J. G.; Demerjian, K. L.; Donahue, N. M. J. Phys. Chem. A 2001, 105, 4446.

(55) Tobias, H. J.; Ziemann, P. J. J. Phys. Chem. A 2001, 105, 6129.

(56) Ziemann, P. J. J. Phys. Chem. A 2003, 107, 2048.

(57) Hasson, A. S.; Orzechowska, G.; Paulson, S. E. J. Geophys. Res. 2001, 106, 34131 .

(58) Hasson, A. S.; Ho, A. W.; Kuwata, K. T.; Paulson, S. E. J. Geophys. Res. 2001, 106, 34143 .

(59) Baker, J.; Aschmann, S. M.; Arey, J.; Atkinson, R. Int. J. Chem. Kinet. 2002, 34, 73.
(60) Kawamura, K. Anal. Chem. 1993, 65, 3505.

(61) Blazso, M.; Janitsek, S.; Gelencser, A.; Artaxo, P.; Graham, B Andreae, M. O. J. Anal. Appl. Pyrolysis 2003, 68-69, 351.

(62) Rogge, W. F.; Hildemann, L. M.; Mazurek, M. A.; Cass, G. R.; Simoneit, B. R. T. Environ. Sci. Technol. 1991, 25, 1112

63) Thornberry, T.; Abbatt, J. P. D. Phys. Chem. Chem. Phys. 2004, 6,

(64) Smith, G. D.; Woods, E., III.; DeForest, C. L.; Baer, T.; Miller, R. E. J. Phys. Chem. A 2002, 106, 8085.

(65) Eliason, T. L.; Gilman, J. B.; Vaida, V. Atmos. Environ. 2004, 38 1367.

(66) Hearn, J. D.; Lovett, A. J.; Smith, G. D. Phys. Chem. Chem. Phys. 2005, 7, 501 .

(67) Katrib, Y.; Martin, S. T.; Hung, H.-M; Rudich, Y.; Zhang, H.; Slowik, J. G.; Davidovits, P.; Jayne, J. T.; Worsnop, D. R. J. Phys. Chem. A 2004, 108, 6686 .

(68) Ziemann, P. J. Faraday Discuss. 2005, 130, 469.

(69) Lai, C. C.; Finlayson-Pitts, B. J.; Willis, W. V. Chem. Res. Toxicol. $1990,3,517$.

(70) Usher, C. R.; Michel, A. E.; Stec, D.; Grassian, V. H. Atmos. Environ. 2003, 37, 5337.

(71) Dubowski, Y.; Vieceli, J.; Tobias, D. J.; Gomez, A.; Lin, A.; Nizkorodov, S. A.; McIntire, T. M.; Finlayson-Pitts, B. J. J. Phys. Chem. A 2004, 108, 10473.

(72) Vieceli, J.; Ma, O. L.; Tobias, D. J. J. Phys. Chem. A 2004, 108, 5806.

(73) Sylvain, C.; Wagner, A.; Mioskowski, C. Tetrahedron Lett. 1997, $38,1043$.

(74) Vallant, T.; Kattner, J.; Brunner, H.; Mayer, U.; Hoffmann, H. Langmuir 1999, 15, 5339.

(75) Cheng, S. S.; Scherson, D. A.; Sukenik, C. N. Langmuir 1995, 11, 1190

(76) Sagiv, J. J. Am. Chem. Soc. 1980, 102, 92.

(77) Mauersberger, K.; Hanson, D.; Barnes, J.; Morton, J. J. Geophys. Res. 1987, 92, 8480 .

(78) Busch, K. W.; Busch, M. A. ACS Symp. Ser. 1999, 720, 7.

(79) Gauss, J.; Cremer, D. Chem. Phys. Lett. 1987, 133, 420.

(80) Cremer, D.; Gauss, J.; Kraka, E.; Stanton, J. F.; Bartlett, R. J. Chem. Phys. Lett. 1993, 209, 547. 7190

Stanton, J. F.; Lopreore, C. L.; Gauss, J. J. Chem. Phys. 1998, 108

(82) Crehuet, R.; Anglada, J. M.; Cremer, D.; Bofill, J. M. J. Phys. Chem A 2002, 106, 3917

(83) Sharpe, S. Vapor phase infrared spectral library (https:// secure.pnl.gov/nsd/nsd.nsf/Welcome); Northwest-Infrared (Battelle-PNNL).

(84) Docherty, K. S.; Wu, W.; Lim, Y. B.; Ziemann, P. J. Environ. Sci. Technol. 2005, 39, 4049 .

(85) Kalberer, M.; Paulsen, D.; Sax, M.; Steinbacher, M.; Dommen, J.; Prevot, A. S. H.; Fisseha, R.; Weingartner, E.; Frankevich, V.; Zenobi, R. Baltensperger, U. Science 2004, 303, 1659.

(86) Jang, M.; Czoschke Nadine, M.; Lee, S.; Kamens Richard, M. Science 2002, 298, 814

(87) Gao, S.; Keywood, M.; Ng, N. L.; Surratt, J.; Varutbangkul, V.; Bahreini, R.; Flagan, R. C.; Seinfeld, J. H. J. Phys. Chem. A 2004, 108, 10147

(88) Gao, S.; Ng, N. L.; Keywood, M.; Varutbangkul, V.; Bahreini, R. Nenes, A.; He, J.; Yoo, K. Y.; Beauchamp, J. L.; Hodyss, R. P.; Flagan, R. C.; Seinfeld, J. H. Environ. Sci. Technol. 2004, 38, 6582.

(89) Tolocka, M. P.; Jang, M.; Ginter, J. M.; Cox, F. J.; Kamens, R. M.; Johnston, M. V. Environ. Sci. Technol. 2004, 38, 1428.

(90) Neeb, P.; Moortgat, G. K. J. Phys. Chem. A 1999, 103, 9003.

(91) Fenske, J. D.; Hasson, A. S.; Paulson, S. E.; Kuwata, K. T.; Ho,

A.; Houk, K. N. J. Phys. Chem. A 2000, 104, 7821.

(92) Hawkins, M.; Kohlmiller, C. K.; Andrews, L. J. Phys. Chem. 1982 86,3154 .

(93) Andrews, L.; Kohlmiller, C. K. J. Phys. Chem. 1982, 86, 4548.

(94) Griesbaum, K.; Volpp, W.; Greinert, R.; Greunig, H. J.; Schmid,

J.; Henke, H. J. Org. Chem. 1989, 54, 383.

(95) Khachatryan, L.; Haas, Y.; Pola, J. Perkin Trans. 1997, 2, 1147.

(96) Schauer, J. J.; Kleeman, M. J.; Cass, G. R.; Simonei, B. R. T. Environ. Sci. Technol. 2002, 36, 567.

(97) Presto, A. A.; Huff Hartz, K. E.; Donahue, N. M. Environ. Sci. Technol. 2005, 39, 7036

(98) Seinfeld, J. H. Private communications, 2005

(99) Knopf, D. A.; Anthony, L. M.; Bertram, A. K. J. Phys. Chem. A 2005, 109, 5579.

(100) Sander, S. P.; Friedl, R. R.; Golden, D. M.; Kurylo, M. J.; Huie, R. E.; L., O. V.; Moortgat, G. K.; Ravishankara, A. R.; Kolb, C. E.; Molina, M. J.; Finlayson-Pitts, B. J. Chemical Kinetics and Photochemical Data for Use in Stratospheric Modeling: Evaluation Number 14, JPL Publication 02-25 ed.; Jet Propulsion Laboratory: Pasedena, 2003. 